\title{
Bank holding companies' earnings management response to the removal of the AOCI filter
}

\author{
Qiuhong Zhao, Ph.D. \\ Assistant Professor of Accounting \\ Email: qiuhong.zhao@tamucc.edu \\ Donald Deis, Ph.D., CPA, CFE \\ Professor of Accounting \\ Email: donald.deis@tamucc.edu \\ College of Business \\ Texas A\&M University-Corpus Christi \\ 6300 Ocean Drive, Unit 5808 \\ Corpus Christi, TX 78412 USA \\ Tel.: +1.361 .825 .3619$ \\ Fax: +1.361 .825 .5609$
}

\begin{abstract}
Our study investigates whether U.S. bank regulators' four-year phased removal of the prudential filter for accumulated other comprehensive income (AOCI) for advanced approaches bank holding companies (AABHCs) affects their use of available-for-sale (AFS) securities, liquidity, or the loan loss provision. We find a decline in the AABHCs selling AFS securities to smooth earnings in the phase-in period (Q1 2014 - Q1 2018). In contrast, non-AABHCs, who mostly exercised an option to retain the AOCI filter, continue to use realized gains and losses as an earnings management tool. We also find that the AOCI filter removal rule did not affect AABHCs liquidity as measured as quarterly bid-ask spreads and price impact under the differencein-difference approach. Finally, we found that AABHCs do not engage in more loan loss provision management after the AOCI filter removal rule. All told, our study extends Kim, Kim, and Ryan (2019) by documenting the consequences of the recent AOCI filter removal rule on bank earnings management behavior through strategic sales of AFS securities. Our findings also contribute to the current debate centering around FASB's postponed requirement (ASU 2016-13) to use the current expected credit loss rule, a mark-to-market approach, to estimate the loan loss provision. More broadly, our paper contributes to the question of whether to base the capital ratios of financial institutions on market-to-market versus historical values (Laux and Leuz 2009, 2010; Hamilton and Schmidt 2020; Isaac 2020).
\end{abstract}

\section{KEYWORDS}

Banks; AOCI filter; regulation, earnings management; available-for-sale securities; realized gains and losses; regulatory capital; liquidity

JEL code: M41, M48, G21 